\title{
Treatment of solid tumors with chimeric antigen receptor- engineered T cells: current status and future prospects
}

\author{
Shengmeng Di \& Zonghai $\mathrm{Li}^{*}$ \\ State Key Laboratory of Oncogenes \& Related Genes, Shanghai Cancer Institute, Renji Hospital, Shanghai Jiaotong University School of \\ Medicine, Shanghai 200032, China
}

Received December 16, 2015; accepted January 19, 2016; published online March 10, 2016

\begin{abstract}
Chimeric antigen receptors (CARs) are artificial recombinant receptors that generally combine the antigen-recognition domain of a monoclonal antibody with $\mathrm{T}$ cell activation domains. Recent years have seen great success in clinical trials employing CD19-specific CAR-T cell therapy for B cell leukemia. Nevertheless, solid tumors remain a major challenge for CAR-T cell therapy. This review summarizes the preclinical and clinical studies on the treatment of solid tumors with CAR-T cells. The major hurdles for the success of CAR-T and the novel strategies to address these hurdles have also been described and discussed.
\end{abstract}

solid tumor, adoptive cell therapy, $T$ cell, chimeric antigen receptor

Citation: Di, S., and Li, Z. (2016). Treatment of solid tumors with chimeric antigen receptor-engineered T cells: current status and future prospects. Sci China Life Sci 59, 360-369. doi: 10.1007/s11427-016-5025-6

\section{INTRODUCTION}

The concept of a chimeric antigen receptor (CAR) was first described by Kuwana and colleagues in 1987 (Diamond et al., 2011). Since its introduction, remarkable improvements have been made to increase the specificity, persistence, and activity of CAR-T cells.

CARs are broadly categorized into three generations. First-generation CARs mediate modified $\mathrm{T}$ cell activation via the $\mathrm{CD} 3$ zeta chain $(\mathrm{CD} 3 \zeta)$ signaling domain, leading to pro-inflamma- tory cytokine secretion, $\mathrm{T}$ cell proliferation, tumor cell lysis in vitro, and the eradication of transplanted tumors in in vivo mouse models. Clinical trials, however, have only shown modest efficacy of first-generation CARs. Incomplete $\mathrm{T}$ cell activation and lack of costimulation are thought to be the primary causes of the weak response in patients; tumors frequently do not provide ligands for costimulatory molecules on $\mathrm{T}$ cells, and the signal through the

*Corresponding author (email: zonghaili@shsmu.edu.cn)
$\mathrm{CD} 3 \zeta$ chain alone is insufficient for priming resting $\mathrm{T}$ cells. Next, second-generation CARs contain costimulatory signaling domains derived from $\mathrm{T}$ cell costimulatory, with receptors such as CD28 being the most common choice. CD28-mediated CAR signaling is preferred in inducing IL-2 secretion and promoting $\mathrm{T}$ cell amplification (Chmielewski et al., 2011). Besides CD28, other costimulatory molecules, such as tumor necrosis factor receptor superfamily member 9 (TNFRSF9, 4-1BB), tumor necrosis factor receptor superfamily, member 4 (TNFRSF9, OX40), inducible T-cell CO Stimulator (ICOS), and CD27, may be included in CAR construction to take advantage of their associated functions in regulating $\mathrm{T}$ cell proliferation, survival, and antitumor response. In particular, 4-1BB costimulation induces IL-2 and IFN- $\gamma$ production and enhances $\mathrm{CD}^{+}{ }^{+} \mathrm{T}$-cell responses. Moreover, $4-1 \mathrm{BB}$ signaling seems to be essential for the persistence of the memory $\mathrm{CD} 8^{+} \mathrm{T}$ cells (Campana et al., 2014). By some researchers, 4-1BB costimulation is considered more effective than CD28 costimulation, as the former reduces exhaustion induced by 
persistent CAR signaling (Annenkov et al., 2002). Nevertheless, an advantage of CD28 signaling is the potential to circumvent CTLA-4 inhibition (Dubinski et al., 2015). Finally, third-generation CARs are constructed from two costimulatory molecular signaling regions. However, more evidence is needed to demonstrate the superiority of third-generation CAR-T cells over second-generation CAR-T cells.

Recent results from clinical trials indicated that CAR-T therapy is remarkably successful in treating hematological malignancies (Davila et al., 2014; Kalos et al., 2011; Lee et al., 2014; Shannon et al., 2014; Maude et al., 2014). However, the benefits of CAR-T cell therapy on solid tumors were far less clear. In this review, we will discuss the current progress in CAR-T cell therapy, including improvements to target antigen specificity, results from preclinical and clinical studies, as well as novel strategies to increase the method's safety and efficacy against solid tumors.

\section{ANTIGEN CHOICE IN SOLID TUMORS}

Tumor antigens targeted by CAR-modified T cells could be cell surface proteins and glycolipids, carbohydrates, and sometimes the major histocompatibility complex 1 (MHC-I). An ideal tumor antigen for CAR-T therapy should target only cancer cells, but few truly tumor-specific anti- gens exist. Most antigen candidates for CAR-T cells are expressed in both tumor cells and some normal cells. Consequently, the selection of tumor antigens requires balancing antitumor efficacy with the risk of "on-target, off-tumor" toxicity in normal tissue. Selecting an appropriate target is a critical step to ensure CAR-T function, as evidenced by the extremely positive outcomes in CAR-T treatments of hematological malignancies, attributed in part to the choice of CD19, an ideal target widely expressed by acute lymphoblastic leukemia cells. While also found in normal cells, CD19 expression is restricted to B cells and their progenitors, allowing the use of gamma-globulin to protect the patients from infection. To date, more than 20 antigens have been used as the targets of CAR-T cells for solid tumors (Table 1). In addition, neoantigens are emerging as possible biomarkers in cancer immunotherapy. Formed by peptides that are entirely absent from the normal human genome, their presence provides an incentive for developing neoantigen-specific CAR-T cells (Schumacher and Schreiber, 2015).

Generally, CAR-T cells recognize and bind to targeted antigens via the single chain antibody expressed on the target cell surface. Thus, antigen intensity appears to be a factor that influences CAR-T cell function. Typically, CAR-T cells target highly expressed antigens while ignoring those that are lowly expressed (Usanarat Anurathapan et al., 2013). This property, however, is a double-edged sword. An

Table 1 Antigens targeted by CAR-T for the treatment of solid tumors

\begin{tabular}{|c|c|c|}
\hline Antigen & Full name & Cancer \\
\hline AC133 & - & Glioblastoma (Liao et al., 2015) \\
\hline B7H6 & - & Ovarian melanoma (Wu et al., 2015c) \\
\hline CAIX & Carbonic anhydrase IX & Metastatic renal cell carcinoma (Lamers et al., 2013) \\
\hline CEA & Carcinoembryonic antigen & pancreatic tumors (Chmielewski et al., 2012) \\
\hline CSPG4 & Chondroitin sulfate proteoglycan-4 & Melanoma, HNSCC, breast carcinoma (Geldres et al., 2013) \\
\hline EGFR & $\begin{array}{l}\text { Type III variant of the epidermal growth factor } \\
\text { receptor }\end{array}$ & Glioblastoma (Miao et al., 2014) \\
\hline EphA2 & $\begin{array}{l}\text { Erythropoietin-producing } \\
\text { hepatocellular A2 }\end{array}$ & $\begin{array}{l}\text { Lung cancer (Kakarla et al., 2013), } \\
\text { glioblastoma (Chow et al., 2013) }\end{array}$ \\
\hline FAP & Fibroblast activation protein & Cancer-associated stromal cells (Yarden and Sliwkowski, 2001) \\
\hline Alpha FR & Alpha folate receptor & Ovarian cancer (Song et al., 2011) \\
\hline GD2 & Disialoganglioside 2 & Neuroblastoma (Craddock et al., 2010; Pule et al., 2008) \\
\hline GPC3 & Glypican-3 & Hepatocellular carcinoma (Gao et al., 2014) \\
\hline Her2 & Human epidermal growth factor receptor 2 & Ovarian cancer (Lanitis et al., 2012a), medulloblastoma (Ahmed et al., 2007) \\
\hline IL13Ra2 & Interleukin-13Ra2 & Glioblastoma (Krebs et al., 2014) \\
\hline L1-CAM (CD171) & Adhesion molecule L1-CAM & $\begin{array}{l}\text { Neuroblastoma, medulloblastoma, ovarian adenocarcinoma (Hong et al., } \\
\text { 2014) }\end{array}$ \\
\hline LMP-1 & Latent membrane protein 1 & nasopharyngeal carcinoma (Tang et al., 2014) \\
\hline Mesothelin & - & Malignant pleural mesotheliomas (Beatty et al., 2014) \\
\hline MUC-1 & - & Breast carcinoma (Wilkie et al., 2008) \\
\hline NKG2D & Natural killer group 2 member D & Ovarian cancer (Spear et al., 2013) \\
\hline PSMA & Prostate specific membrane antigen & Prostate cancer (Stephan et al., 2007) \\
\hline PSCA & Prostate stem cell antigen & Pancreatic cancer (Abate-Daga et al., 2014) \\
\hline TRAIL-receptor 1 & $\begin{array}{l}\text { TNF-related apoptosis-inducing ligand } \\
\text { (TRAIL) receptor } 1\end{array}$ & Colon cancer, ovarian cancer (Kobayashi et al., 2014) \\
\hline VEGFR-1 & Vascular endothelial growth factor receptor-1 & Neovascularization (Wang et al., 2013) \\
\hline EGFR & Epidermal growth factor receptor & Epithelial carcinoma, non-small cell lung cancer (Zhou et al., 2013) \\
\hline
\end{tabular}


advantage is the avoidance of on-target, off-tumor toxicity, as normal tissues often express low levels of tumorassociated antigens. However, a clear disadvantage is the failure of lowly expressed of antigens to fully activate CAR-T cells, which then cannot efficiently eliminate tumor cells with low densities of target antigens.

\section{PRECLINICAL STUDIES}

CAR-T cells targeting several tumor-associated antigens have been advanced into clinical trials. Here, we describe several preclinical studies on these target-redirected CAR-T cells.

\section{Her-2-specific CAR-T cells}

Human epidermal growth factor receptor 2 (Her-2, also called neu or ErbB2) is a member of the epidermal growth factor receptor (EGFR) family. It is one of the most commonly studied tumor-associated antigens for cancer immunotherapy, as it is widely expressed on medulloblastoma, osteosarcoma, glioblastoma, and breast cancer cells. Initial studies using N29, a first-generation CAR derived from Her2-specific scFv, demonstrated specificity and lysis activity dependent on Her2 presence (Stancovski et al., 1993). Another such CAR (FRP5) resulted in sustained regression of established medulloblastomas in an orthotopic, xenogeneic mouse model (Ahmed et al., 2007). Subsequent data confirmed the functionality of second-generation (CD28) CARs expressing canine $\mathrm{T}$ cells on Her- $2^{+}$osteosarcoma (Mata et al., 2014). Further study revealed that CD28modified second-generation CAR-T cells significantly inhibited tumor growth in mice bearing osteosarcoma or breast tumor xenografts (Sun et al., 2014). Taken together, these results highlight the clinical potential of Her-2 targeted CAR-T therapy.

\section{EGFRvIII-specific CAR-T cells}

The epidermal growth factor receptor variant III (EGFRvIII) is an oncogenic variant of EGFR, absent in normal tissue but exclusively expressed in tumors from several cancer types, including glioblastoma (GBM), breast cancer, and non-small cell lung cancer (NSCLC). Most EGFRvIII-redirected CAR-T studies were assessed in glioblastoma models. Early preclinical studies demonstrated the potential antitumor effect of first-generation CARs targeting EGFRvIII (González-Navajas et al., 2012; Jacoby et al., 2015). Subsequent second- and third-generation CAR-T cells validated their antitumor activity on EGFRvIII ${ }^{+}$glioblastoma cells. Furthermore, intracerebral injection of thirdgeneration CAR-T cells successfully inhibited tumor growth (Choi et al., 2014). Intriguingly, after systemic delivery, EGFRvIII-targeted third-generation CAR-T cells could localize to intracranial tumors, suppress tumor growth, and enhance the survival of mice carrying established GBM xenografts (Miao et al., 2014).

\section{Mesothelin-specific CAR-T cells}

Mesothelin is a tumor-associated antigen that is overexpressed in many cancer types (e.g., malignant pleural mesotheliomas (MPM), pancreatic cancers, and ovarian cancers) and lowly expressed on normal peritoneal, pleural, as well as pericardial mesothelial surfaces (Beatty et al., 2014). Thus, immunotherapy that targets mesothelin has yielded promising results. For example, a recent study (Carpenito et al., 2009) engineered T cells with high affinity for mesothelin $(\mathrm{CD} 28-41 \mathrm{BBz})$ and transferred them intratumorally or intravenously into immunodeficient mice, engrafted with tumors pre-established by serial passage of primary pleural effusion cells from mesothelioma patients. As a result, the engineered $\mathrm{T}$ cells reduced the tumor burden and in some cases completely eradicated the tumors at low effector-to-target ratios (Carpenito et al., 2009). Similarly, intratumoral injection of RNA CAR electroporated T cells mediated regression of large, vascularized flank-mesothelioma tumors in mice (Zhao et al., 2010), although these T cells are less potent in the same model than lentivirus-transduced T cells, which cure most mice (Carpenito et al., 2009). Furthermore, adoptive transfer of mesothelin-targeted firstgeneration CAR-T cells mediated regression of ovarian cancer in a xenogeneic model (Lanitis et al., 2012b). These findings support the potent clinical application of mesothelin-specific CAR-T cells for MPM, ovarian cancer, and other solid tumors.

\section{GD2-specific CAR-T cells}

Ganglioside GD2 is a tumor-associated surface antigen found in a broad spectrum of human cancers and stem cells, including pediatric embryonal tumors and adult cancers. Because its distribution in normal tissue is restricted, GD2 is safe for immunotherapy targeting (Krug et al., 2015). Third-generation CAR-T cells, based on GD2-specific antibody sc14.G2a, secreted significant levels of cytokines upon antigen recognition and exhibited anti-melanoma activity both in vitro and in xenograft models (Yvon et al., 2009). Additionally, first-generation CAR-T cells coexpressing chemokine receptor CCR2b was constructed and improved homing, as well as greater anti-tumor activity, to CCL2-secreting GD2 ${ }^{+}$neuroblastoma in vivo was observed (Craddock et al., 2010).

\section{CEA-specific CAR-T cells}

CEA is a $180-\mathrm{kD}$ tumor-associated glycoprotein. It is a well-known tumor-inducer that is overexpressed in many epithelial cancers, most notably in colorectal adenocarcinoma and pancreatic tumors. A recent study reported rejection of carcinoembryonic antigen (CEA)-positive pancreatic tumors in CEA-transgenic mice that expressed CEA as selfantigen in healthy gastrointestinal cells (Chmielewski et al., 
2012). Adoptive therapy with CEA-targeted first-generation CAR-T cells eliminated $\mathrm{CEA}^{+}$tumors in a primary response. Moreover, upon rechallenge, cured mice produced an efficient, long-term recall response towards $\mathrm{CEA}^{+}$tumor cells. The antitumor response of CD28-costimulatory CAR-T cells was also validated in an animal model for $\mathrm{CEA}^{+}$colorectal cancer (Emtage et al., 2008).

\section{EphA2-specific CAR-T cells}

EphA2 has emerged as an attractive target for GBM immunotherapy because it is overexpressed in glioma and promotes malignancy. Studies found that EphA2 signaling plays an important role in glioma cell proliferation (Liu et al., 2006), migration, and invasion (Miao et al., 2009). EphA2-specific CAR-T cells (CD28z) could recognize EphA2-positive glioma cells and were potent against human glioma-initiating cells, preventing neurosphere formation and destroying intact neurospheres in coculture assays. Additionally, adoptive transfer of EphA2-specific CAR-T cells resulted in the regression of glioma xenografts in a mouse model (Chow et al., 2013). When combined with FAP (fibroblast activation protein)-specific $\mathrm{T}$ cells (CD28z), these EphA2 specific CAR-T cells significantly enhanced overall antitumor activity and conferred a survival advantage over either treatment alone (Kakarla et al., 2013).

\section{NK cell activating receptor-based CAR-T cells}

It is well known that NK cells employ activating receptors, such as NKG2D, NKp30, and DNAX accessory molecule-1 (DNAM-1), to recognize stress-induced ligands expressed on various tumor types. Therefore, CARs composed of the ligand-binding region of these receptors or the scFv against these ligands were developed and the resulted CAR-T cells have been evaluated in preclinical animal models, with encouraging antitumor results (Wu et al., 2015b, 2015c; Zhang et al., 2012). However, sometimes lethal toxicity was observed (VanSeggelen et al., 2015).

Beside these commonly used targets, many other antigens are emerging as potential CAR-T targets in solid tumors. For example, we demonstrated that GPC3 is a suitable antigen for the development of CAR-T cells to treat hepatocellular carcinoma (Gao et al., 2014) and lung squamous non-small cell lung cancer (Li K, et al., 2015). Other research has shown that interleukin-13Ra2 specific CAR-T cells may be used to eliminate glioblastoma (Krebs et al., 2014). In general, existing preclinical data strongly indicate that CAR-T cells are extremely robust antitumor reagents.

\section{CLINICAL TRIALS}

To date, about 40 clinical trials using CAR-T to treat solid tumors have been performed (Table 2). These clinical trials include first-, second-, and third-generation CAR-T cells.

\section{First-generation CAR-T cells}

As early as 2006, Kershaw et al. conducted a phase I clinical trial using CAR-T cells to target the ovarian cancer-associated antigen, $\alpha$-folate receptor (FR) (Kershaw et al., 2006). However, tumor burden was not reduced in any patient after infusion with first-generation CAR-T. In the same year, Lamers et al. reported another clinical trial that treated metastatic clear cell renal cell carcinoma (RCC) using carboxy-anhydrase-IX (CAIX)-targeted CAR-T cells (Lamers et al., 2006). An unexpected liver toxicity was observed, caused by the CAR-T cells attacking the CAIX ${ }^{+}$bile duct epithelial cells. This study demonstrated that CAR-T cells redirected to targets shared by normal and cancer cells would cause on-target off-tumor toxicity. Thus, to reduce such risks, additional safety mechanisms must be incorporated into these CARs to reduce the risk. However, another clinical trial using first-generation CAR-T cells targeting L1-cell adhesion molecule (L1-CAM) also showed no significant toxicities and toxicities and limited efficacy when treating six children with recurrent/refractory neuroblastoma (Park et al., 2007). Besides on-target off-tumor side effects, infused CAR-T cells may be immunogenic because of the associated transgene and the retroviral vector-encoded epitopes (Lamers et al., 2011). Thus. it is essential to attenuate the immunogenicity of both transgene and vector.

Generally, the first-generation CAR-T cells do not survive well in vivo. Therefore, Epstein-Bar virus (EBV)specific CTLs were engineered to express a chimeric antigen receptor directed at the disialoganglioside GD2, a tumor-associated antigen expressed by human neuroblastoma cells (Pule et al., 2008). They found that virus-specific CAR-T cells persisted in higher numbers and for longer periods after infusion to patients than CAR-T cells that lack EBV specificity (Pule et al., 2008). The characteristics associated with virus-specific CAR-T cells were linked to subsequent tumor necrosis or sustained complete remission. Thus, virus-specific CAR-T cells may offer distinct advantages as tumor- directed effector cells.

\section{Second- and third-generation CAR-T cells}

Several second- and third-generation CAR-T cells have advanced into clinical trials. As one example, a phase I/II clinical study was conducted in which patients with recurrent/refractory sarcoma received escalating doses of $\mathrm{T}$ cells expressing an Her2-specific chimeric antigen receptor, with a CD28-CD3ל signaling domain (Ahmed et al., 2015). Although the second-generation Her2-CAR-T cells persisted for six weeks in patients without evident toxicity, the clinical outcome was limited. Third-generation CARs specific to Her2 was also tested in clinical trials. However, these CARs caused lethal on-target, off-tumor toxicity in a patient with colon cancer (Morgan et al., 2010). This serious side effect prompted researchers to modify CAR-T cells with a "safety switch" to limit toxicity. Such switches include caspase-9 
Table 2 Summary of CAR-T clinical trials in solid tumors ${ }^{\text {a) }}$

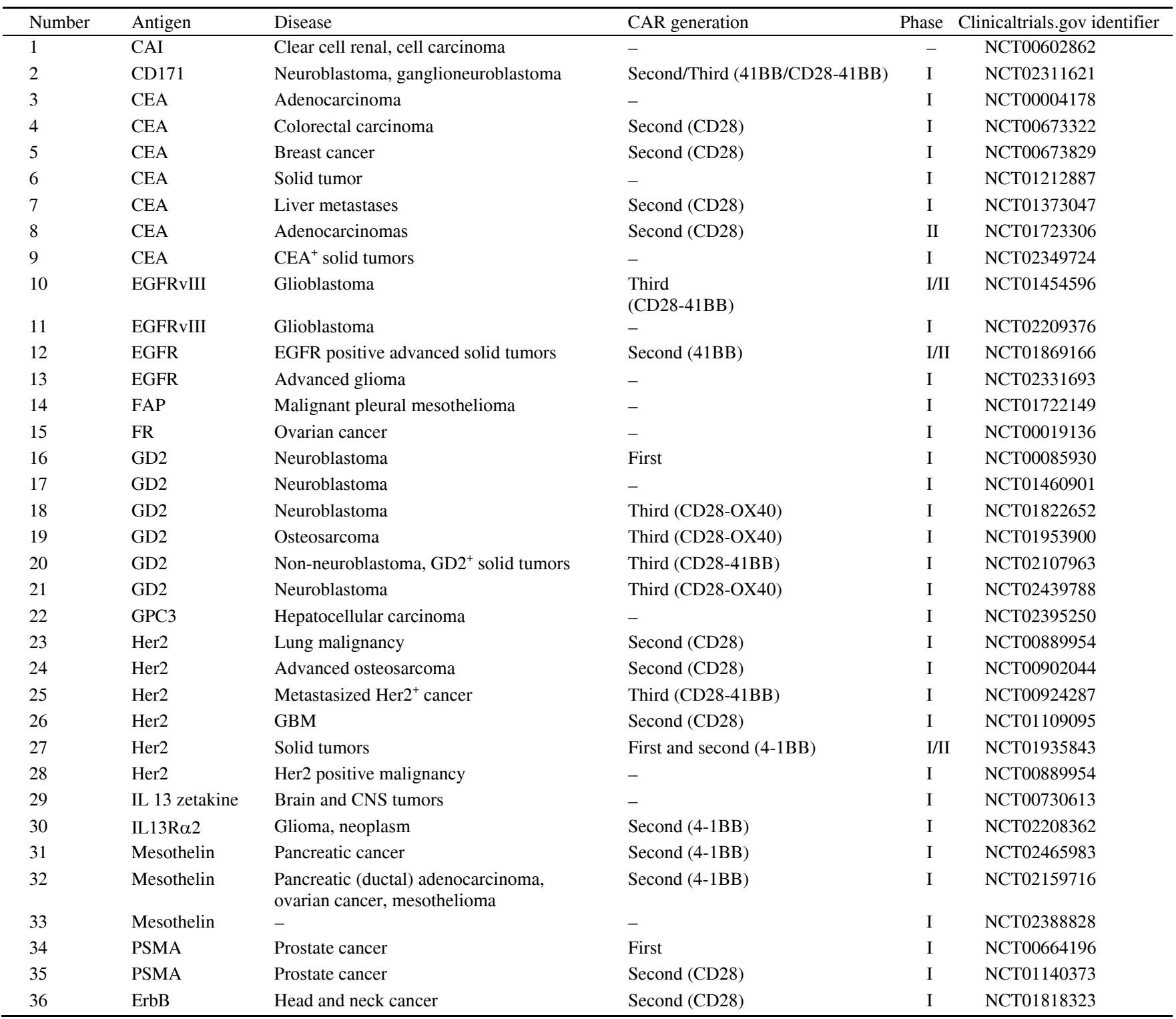

a) From https://www.clinicaltrials.gov/.

(Gargett and Brown, 2014), caspase-8 (Khaleghi et al., 2012), Herpes simplex thymidine kinase (Hsv-tk) (Jensen et al., 2010), and CD20 suicide genes (Burnette et al., 2011).

Recently, six patients (with chemotherapy-refractory metastatic pancreatic ductal adenocarcinoma) were treated with autologous $\mathrm{T}$ cells, transiently expressing a mesothelin-specific CAR that includes both CD3 $\zeta$ and 4-1BB costimulatory domains (Beatty et al., 2015). Of the administered CAR-T cell infusions, $98 \%$ showed no dose-limiting toxicity. Infusions were well tolerated, without evidence of cytokine release syndrome, pleuropericarditis, or peritonitis. Two of the six patients were categorized as experiencing stable disease under RECIST 1.1 guidelines, and in one patient, liver metastases were no longer detected after therapy. These outcomes suggest that the CARmeso $\mathrm{T}$ cells successfully exhibited antitumor activity. Additionally, T cells bearing bispecific CAR were also applied to treat patients with progressive Her2 $2^{+}$GBM (Nabil et al., 2015). Only one out of fifteen patients exhibited partial response and four patients had stable disease after CAR-T infusion.

Overall, the results of clinical trials have demonstrated that CAR-T cells do exhibit antitumor activity in humans. However, clinical responses to CAR-T cell treatment of solid tumors are generally far from satisfactory. Therefore, considerable effort must still be made to increase the safety and efficacy of CAR-T cell therapy.

\section{NOVEL STRATEGIES TO INCREASE THE SAFETY AND EFFICACY OF CAR-T}

The difference in the clinical responses between solid tumors and blood cancers, especially leukemia, is very obvi- 
ous. There are at least four important reasons for this great difference. The first reason is that CAR-T cells cannot easily penetrate solid tumor tissues to fight the cancer. The second reason is that a solid tumor represents an extremely hostile microenvironment that hampers the infiltration, expansion, survival of the CAR-T cells, because tumoreducated immune cells, mesenchymal cells, and vascular endothelial cells are present along with tumor cells. The third reason is that cancer cells and the target antigens in the solid tumor are generally heterogeneous, which negatively affects CAR-T cell antitumor activities. The fourth reason is that cancer-specific antigens in solid tumor are very limited. All of these problems contribute to on-target off-tumor toxicity, which undeniably limits the therapeutic window of CAR-T cells. Thus, considerable effort is being exerted to develop a variety of strategies aimed at improving the safety and efficacy of CAR-T cell therapy.

\section{Enhanced accumulation of CAR-T cells into the tumor tissues}

Several strategies have been designed to increase CAR-T cell migration to the tumor site. One strategy is to engineer $\mathrm{T}$ cells with chemokine receptors. For instance, Kershaw et al. showed that deficiencies in $\mathrm{T}$ cell chemotaxis towards tumor cells are overcome by transgenic CXCR2 expression, facilitating the recognition of tumor-produced Gro$\alpha$ (Kershaw et al., 2002). Likewise, results from murine xenograft experiments demonstrated that overexpression of the chemokine receptor CCR4 by CD30-specific CAR-T cells enhances their migration into Hodgkin's lymphoma (Di Stasi et al., 2009). Moreover, CCR2b-modified CAR-T cells redirected to GD2 have improved tumor-specific trafficking and significantly enhanced activity against neuroblastoma xenografts (Craddock et al., 2010).

Although chemokine receptor modification improves CAR-T cell migration to tumor sites, it does little to promote cell extravasation, necessary for eventual contact between the effector cells and the target tumor cells. To solve this issue, one study incorporated echistatin into CAR-T cells (Fu et al., 2013). Echistatin binds strongly to $\alpha v \beta 3$ integrin, which is highly expressed on the surface of endothelial cells from tumor neovasculature. The echistatin-modified CAR-T was then able to lyse human umbilical vein endothelial cells and tumor cells that express $\alpha v \beta 3$ efficiently in vitro. Additionally, systemic administration of echistatin-modified CAR-T cells led to extensive bleeding in tumor tissues with no evidence of damage to blood vessels in normal tissues.

Recently, CAR-T cells were found to lose heparanase (HPSE) expression after in vitro culture. Heparanase degrades heparin sulfate proteoglycans, the main components of the extracellular matrix. Thus, re-expression of HSPE in CAR-T cells significantly improved their $\mathrm{T}$ cell infiltration and antitumor activities (Caruana et al., 2015). Another method of improving CAR-T penetration into tumors is the use of cancer-associated fibroblasts (CAF). Specifically, a recent finding revealed that $\mathrm{FAP}$-specific CAR-T cells, capable of destroying FAP-positive fibroblast cells, could increase the antitumor activity of EphA2-targeted CAR-T cells in lung cancer models (Kakarla et al., 2013).

\section{Armored cytokines to increase immune response}

Most immunotherapy trials yield primarily transient tumor regression, likely because we tend to neglect the heterogeneity of tumor lesions at the immunologic level. CAR-T cells themselves are not able to lyse target-negative tumor cells directly. Therefore, it seems necessary to equip CAR-T cells with cytokines such as IL-12, which play a pivotal role in immunoregulatory functions. To mediate tumor lysis, IL-12 can augment the activation of cytotoxic $T$ cells and NK cells, both primary effectors of the adaptive and innate immune responses. A recent study has demonstrated the effectiveness of this method; CEA-specific CAR-T cells, carrying an $\mathrm{NFAT}_{6}$-induced IL-12 transgene, were able to eradicate mixed CEA-positive and CEA-negative tumor cells (Watford et al., 2003).

\section{Optimization of costimulatory signals}

Although CD28 and 4-1BB are the most commonly used costimulatory molecules, less conventional options, such as MyD88 and CD40, may ultimately prove to be more suitable for CAR-T cell immunotherapy. In a recent report, MyD88/CD40 was able to promote higher levels of IL2 production in CAR-T cells than CD28 (Lasek et al., 2014). CAR-T cells bearing MYD88/CD40 signals also display enhanced efficacy in $\mathrm{CD}_{1} 9^{+}$and Her2 $2^{+}$tumor models, respectively, compared with CAR-T cells bearing the CD28 signal. Costimulation with MYD88 or CD40 resulted in greater $\mathrm{T}$ cell proliferation, cytokine production, and antitumor efficacy in vivo than control CARs with standard costimulatory molecules. Similarly, CD40L-modified CAR-T (CD28-CD3 $)$ ) exhibited more antitumor activity in a xenotransplant model of $\mathrm{CD} 19^{+}$systemic lymphoma than

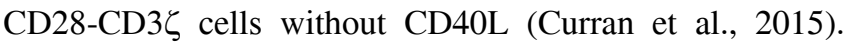
Finally, T lymphocytes armed with the uncommonly used CD80 and 4-1BBL provoked potent rejection of large, systemic tumors in a xenotransplant model of PSMA ${ }^{+}$prostate cancer (Stephan et al., 2007).

\section{Regional delivery of CAR-T cells}

Taking advantage of an orthotopic model that faithfully mimics human pleural malignancy, Adusumilli et al. used M28z CAR to evaluate two routes of mesothelin-targeted T cell administration (Adusumilli et al., 2014). They found that intrapleurally administered CAR-T cells vastly outperformed systemically infused $\mathrm{T}$ cells, requiring 30-fold fewer M28z T cells to induce long-term, complete remission. After intrapleural $\mathrm{T}$ cell administration, prompt in vivo antigen-induced $\mathrm{T}$ cell activation allowed robust CAR-T cell 
expansion and effector differentiation, resulting in enhanced antitumor efficacy and functional T cell persistence for 200 days. Regional T cell administration also promoted the efficient elimination of extrathoracic tumor sites. The ability of intrapleurally administered $\mathrm{T}$ cells to circulate and persist within the periphery opens new avenues of treatment for metastatic cancers with accessible tumor sites, which may serve as "regional charging and distribution centers" for CAR-T cell therapy. Appropriate candidates include cancers that metastasize to the pleural cavity, such as lung and breast cancers, as well as those that metastasize to the peritoneal cavity, such as pancreatic and ovarian cancers. In addition to intrapleural or intraperitoneal administration, Choi et al. implanted EGFRvIII CAR-T cells intracerebrally and successfully treated glioma in mice (Choi et al., 2014).

At the very least, this approach may decrease the $\mathrm{T}$ cell dose requirement, presenting an advantage when high numbers of CAR-T cells are not attainable (i.e., due to low-yield apheresis, poor ex vivo expansion, or low transduction). In the best case, regional delivery may even obviate the need for systematic apheresis.

\section{Increasing the safety index of CARs}

The importance of successfully redirecting CAR-T cells to cancer tissues and away from normal tissues cannot be overestimated, because doing so reduces toxicity and increases the therapeutic window. However, as stated previously, cancer-specific antigens like EGFRvIII are very rare. Therefore, numerous strategies have been developed to increase the safety of CAR-T cell therapy. One popular and clinically tested method of controlling CAR-T cells in vivo is to include suicide switches in the vectors used to engineer $\mathrm{T}$ cells. For instance, the caspase switch efficiently eliminates T cells in patients (Di Stasi et al., 2011; Russo et al., 2012), and the "tumor sensing" approach, which combines two types of antigen recognition with balanced signaling, can potentially reduce on-target off-tumor toxicity (Kloss et al., 2013). Yet another way to circumvent on-target off-tumor toxicity is the recently developed antigen-specific inhibitory chimeric antigen receptors (iCARs) technology (Fedorov et al., 2013). The iCAR has a surface antigen recognition domain combined with a powerful acute inhibitory signaling domain to limit $\mathrm{T}$ cell responsiveness despite engagement of an activating receptor. This study demonstrated that CTLA-4- or PD-1-based iCAR could temporarily and selectively limit cytotoxicity induced through the endogenous $\mathrm{T}$ cell receptor or an activating chimeric receptor.

Promising methods to increase the therapeutic window include TanCAR, which mediates bispecific activation and targeting of $\mathrm{T}$ cells. This novel receptor produces synergistic enhancement of effector functions when encountering two antigens and preserves cytolytic ability upon the loss of one target (Grada et al., 2013). In addition, fine-tuning CAR-T cell affinities may increase their therapeutic index, as low-affinity CAR-T cells appear capable of discriminat- ing tumor cells with high EGFR or Her2 expression from tumors with low expression (Caruso et al., 2015; Liu et al., 2015).

\section{Combination with immune checkpoint inhibitors}

The expression and activity of immune checkpoints significantly affect the survival and function of the CAR-T cells. Thus, a potential method of increasing CAR-T cell activity is a combination with immune checkpoint inhibitors. For instance, adding an anti-PDL1 antibody significantly restored the killing activity of CAR-T cells (Moon et al., 2014). Notably, anti-CTLA-4 and anti-PD-1 antibodies have shown clinical promise by derepressing anti-T cell responses in some patients with melanoma, lung, and renal cancer (Carosella et al., 2015). However, researchers have not fully explored the efficacy of joint therapeutic techniques involving both CAR-T cells and immunomodulatory agents such as the anti CTLA-4 or PD-1 checkpoint inhibitors.

\section{FUTURE DIRECTIONS AND CONCLUDING REMARKS}

In this review, we summarized the current preclinical and clinical studies on CAR-T therapy against solid tumors. Although the results of clinical studies have thus far yielded limited achievements, we are confident in the potential of solid tumor treatments using CAR-T. We should bear in mind that CAR-T is completely different from other current antitumor therapies, including antibodies and smallmolecule drugs. There is tremendous scope for increasing CAR-T cell efficacy and safety, but this cannot be achieved without further clinical trials to validate treatment and tailor them to patients appropriately. Moreover, CAR-T cells are amenable to combinations with other therapy options. For example, low dose irradiation may be used to promote CAR-T infiltration into tumor tissues (Wu et al., 2015a). In conclusion, we believe that with increased effort and attention, CAR-T cells will soon become a potent and efficient treatment method for solid tumors.

Compliance and ethics The author(s) declare that they have no conflict of interest.

Acknowledgements This work was supported by the Supporting Programs of the Research Fund of the State Key Laboratory of Oncogenes and Related Genes (91-14-12), the Shanghai Science and Technology Development Funds (12JC1408300), the Shanghai Rising-Star Program (A type; 13QA1403300), and the One Hundred Talents Scientific Research Projects of Health Systems in Shanghai (XBR2013123).

Abate-Daga, D., Lagisetty, K.H., Tran, E., Zheng, Z., Gattinoni, L., Yu, Z., Burns, W.R., Miermont, A.M., Teper, Y., Rudloff, U., Restifo, N.P., Feldman, S.A., Rosenberg, S.A., and Morgan, R.A. (2014). A novel chimeric antigen receptor against PSCA mediates tumor destruction in a humanized mouse model of pancreatic cancer. Hum Gene Ther 25, 1003-1012. 
Adusumilli, P.S., Cherkassky, L., Villena-Vargas, J., Colovos, C., Servais, E., Plotkin, J., Jones, D.R., and Sadelain, M. (2014). Regional delivery of mesothelin-targeted CAR $\mathrm{T}$ cell therapy generates potent and long-lasting CD4-dependent tumor immunity. Sci Transl Med 6, 261 ra151.

Ahmed, N., Brawley, V.S., Hegde, M., Robertson, C., Ghazi, A., Gerken, C., Liu, E., Dakhova, O., Ashoori, A., Corder, A., Gray, T., Wu, M.F., Liu, H., Hicks, J., Rainusso, N., Dotti, G., Mei, Z., Grilley, B., Gee, A., Rooney, C.M., Brenner, M.K., Heslop, H.E., Wels, W.S., Wang, L.L., Anderson, P., and Gottschalk, S. (2015). Human epidermal growth factor receptor 2 (HER2)-specific chimeric antigen receptor-modified T cells for the immunotherapy of HER2-positive sarcoma. J Clin Oncol 33: $1688-1696$.

Ahmed, N., Ratnayake, M., Savoldo, B., Perlaky, L., Dotti, G., Wels, W.S., Bhattacharjee, M.B., Gilbertson, R.J., Shine, H.D., Weiss, H.L., Rooney, C.M., Heslop, H.E., and Gottschalk, S. (2007). Regression of experimental medulloblastoma following transfer of HER2-specific T cells. Cancer Res 67, 5957-5964

Annenkov, A.E., Daly, G.M., and Chernajovsky, Y. (2002). Highly efficient gene transfer into antigen-specific primary mouse lymphocytes with replication-deficient retrovirus expressing the 10A1 envelope protein. J Gene Med 4, 133-140.

Beatty, G., O’Hara, M., Nelson, A., McGarvey, M., Torigian, D., Lacey, S., Melenhorst, J., Levine, B., Plesa, G., and June, C. (2015). Safety and antitumor activity of chimeric antigen receptor modified $\mathrm{T}$ cells in patients with chemotherapy refractory metastatic pancreatic cancer. J Clin Oncol 33, 3007.

Beatty, G.L., Haas, A.R., Maus, M.V., Torigian, D.A., Soulen, M.C., Plesa, G., Chew, A., Zhao, Y., Levine, B.L., Albelda, S.M., Kalos, M., and June, C.H. (2014). Mesothelin-specific chimeric antigen receptor mRNA-engineered $\mathrm{T}$ cells induce anti-tumor activity in solid malignancies. Cancer Immunol Res 2, 112-120.

Burnette, B.C., Liang, H., Lee, Y., Chlewicki, L., Khodarev, N.N., Weichselbaum, R.R., Fu, Y.-X., and Auh, S.L. (2011). The efficacy of radiotherapy relies upon induction of type I interferon-dependent innate and adaptive immunity. Cancer Res 71, 2488-2496.

Campana, D., Schwarz, H., and Imai, C. (2014). 4-1BB chimeric antigen receptors. Cancer J 20, 134-140.

Carosella, E.D., Ploussard, G., LeMaoult, J., and Desgrandchamps, F. (2015). A systematic review of immunotherapy in urologic cancer: evolving roles for targeting of CTLA-4, PD-1/PD-L1, and HLA-G. Euro Urol 68, 267-279.

Carpenito, C., Milone, M.C., Hassan, R., Simonet, J.C., Lakhal, M., Suhoski, M.M., Varela-Rohena, A., Haines, K.M., Heitjan, D.F., Albelda, S.M., Carroll, R.G., Riley, J.L., Pastan, I., and June, C.H. (2009). Control of large, established tumor xenografts with genetically retargeted human T cells containing CD28 and CD137 domains. Proc Natl Acad Sci USA 106, 3360-3365.

Caruana, I., Savoldo, B., Hoyos, V., Weber, G., Liu, H., Kim, E.S., Ittmann, M.M., Marchetti, D., and Dotti, G. (2015). Heparanase promotes tumor infiltration and antitumor activity of CAR-redirected T lymphocytes. Nat Med 21, 524-529.

Caruso, H.G., Hurton, L.V., Najjar, A., Rushworth, D., Ang, S., Olivares, S., Mi, T., Switzer, K., Singh, H., Huls, H., Lee, D.A., Heimberger, A.B., Champlin, R.E., and Cooper, L.J. (2015). Tuning sensitivity of CAR to EGFR density limits recognition of normal tissue while maintaining potent antitumor activity. Cancer Res 75, 3505-3518.

Chmielewski, M., Hombach, A.A., and Abken, H. (2011). CD28 cosignalling does not affect the activation threshold in a chimeric antigen receptor-redirected T-cell attack. Gene Ther 18, 62-72.

Chmielewski, M., Rappl, G., Hombach, A.A., and Abken, H. (2012). T cells redirected by a CD3zeta chimeric antigen receptor can establish self-antigen-specific tumour protection in the long term. Gene Ther 20, 177-186

Choi, B.D., Suryadevara, C.M., Gedeon, P.C., Herndon II, J.E., Sanchez-Perez, L., Bigner, D.D., and Sampson, J.H. (2014). Intracerebral delivery of a third generation EGFRvIII-specific chimeric antigen receptor is efficacious against human glioma. J Clin Neurosci $21,189-190$
Chow, K.K., Naik, S., Kakarla, S., Brawley, V.S., Shaffer, D.R., Yi, Z., Rainusso, N., Wu, M.F., Liu, H., Kew, Y., Grossman, R.G., Powell, S., Lee, D., Ahmed, N., and Gottschalk, S. (2013). T cells redirected to EphA2 for the immunotherapy of glioblastoma. Mol Ther 21, 629-637.

Craddock, J.A., Lu, A., Bear, A., Pule, M., Brenner, M.K., Rooney, C.M., and Foster, A.E. (2010). Enhanced tumor trafficking of GD2 chimeric antigen receptor $\mathrm{T}$ cells by expression of the chemokine receptor CCR2b. J Immunother 33, 780-788.

Curran, K.J., Seinstra, B.A., Nikhamin, Y., Yeh, R., Usachenko, Y., van Leeuwen, D.G., Purdon, T., Pegram, H.J., and Brentjens, R.J. (2015). Enhancing anti-tumor efficacy of chimeric antigen receptor $\mathrm{T}$ cells through constitutive CD40L expression. Mol Ther 23, 769-778.

Davila, M.L., Riviere, I., Wang, X., Bartido, S., Park, J., Curran, K., Chung, S.S., Stefanski, J., Borquez-Ojeda, O., Olszewska, M., Qu, J., Wasielewska, T., He, Q., Fink, M., Shinglot, H., Youssif, M., Satter, M., Wang, Y., Hosey, J., Quintanilla, H., Halton, E., Bernal, Y., Bouhassira, D.C., Arcila, M.E., Gonen, M., Roboz, G.J., Maslak, P., Douer, D., Frattini, M.G., Giralt, S., Sadelain, M., and Brentjens, R. (2014). Efficacy and toxicity management of 19-28z CAR T cell therapy in B cell acute lymphoblastic leukemia. Sci Transl Med 6, $224 \mathrm{ra} 225$.

Di Stasi, A., De Angelis, B., Rooney, C.M., Zhang, L., Mahendravada, A., Foster, A.E., Heslop, H.E., Brenner, M.K., Dotti, G., and Savoldo, B. (2009). T lymphocytes coexpressing CCR4 and a chimeric antigen receptor targeting CD30 have improved homing and antitumor activity in a Hodgkin tumor model. Blood 113, 6392-6402.

Di Stasi, A., Tey, S.K., Dotti, G., Fujita, Y., Kennedy-Nasser, A., Martinez, C., Straathof, K., Liu, E., Durett, A.G., Grilley, B., Liu, H., Cruz, C.R., Savoldo, B., Gee, A.P., Schindler, J., Krance, R.A., Heslop, H.E., Spencer, D.M., Rooney, C.M., and Brenner, M.K. (2011). Inducible apoptosis as a safety switch for adoptive cell therapy. N Engl J Med 365, 1673-1683.

Diamond, M.S., Kinder, M., Matsushita, H., Mashayekhi, M., Dunn, G.P., Archambault, J.M., Lee, H., Arthur, C.D., White, J.M., and Kalinke, U. (2011). Type I interferon is selectively required by dendritic cells for immune rejection of tumors. J Exp Med 208, 1989-2003.

Dubinski, D., Wölfer, J., Hasselblatt, M., Schneider-Hohendorf, T., Bogdahn, U., Stummer, W., Wiendl, H., and Grauer, O.M. (2015). $\mathrm{CD}^{+} \mathrm{T}$ effector memory cell dysfunction is associated with the accumulation of granulocytic myeloid-derived suppressor cells in glioblastoma patients. Neuro Oncol pii: nov280.

Emtage, P.C., Lo, A.S., Gomes, E.M., Liu, D.L., Gonzalo-Daganzo, R.M., and Junghans, R.P. (2008). Second-generation anti-carcinoembryonic antigen designer $\mathrm{T}$ cells resist activation-induced cell death, proliferate on tumor contact, secrete cytokines, and exhibit superior antitumor activity in vivo: a preclinical evaluation. Clin Cancer Res 14, 8112-8122.

Fedorov, V.D., Themeli, M., and Sadelain, M. (2013). PD-1- and CTLA-4-based inhibitory chimeric antigen receptors (iCARs) divert off-target immunotherapy responses. Sci Transl Med 5, 215 ra172.

Fu, X., Rivera, A., Tao, L., and Zhang, X. (2013). Genetically modified T cells targeting neovasculature efficiently destroy tumor blood vessels, shrink established solid tumors, and increase nanoparticle delivery. Int J Cancer 133, 2483-2492.

Gao, H., Li, K., Tu, H., Pan, X., Jiang, H., Shi, B., Kong, J., Wang, H., Yang, S., Gu, J., and Li, Z. (2014). Development of T cells redirected to glypican-3 for the treatment of hepatocellular carcinoma. Clin Cancer Res 20, 6418-6428.

Gargett, T., and Brown, M.P. (2014). The inducible caspase-9 suicide gene system as a "safety switch" to limit on-target, off-tumor toxicities of chimeric antigen receptor T cells. Front Pharmacol 5, 235.

Geldres, C., Savoldo, B., Hoyos, V., Caruana, I., Zhang, M., Yvon, E., Del Vecchio, M., Creighton, C.J., Ittmann, M.M., Ferrone, S., and Dotti, G. (2013). T lymphocytes redirected against the chondroitin sulfate proteoglycan-4 control the growth of multiple solid tumors both in vitro and in vivo. Clin Cancer Res 20, 962-967.

González-Navajas, J.M., Lee, J., David, M., and Raz, E. (2012). Immunomodulatory functions of type I interferons. Nat Rev Immunol $12,125-135$. 
Grada, Z., Hegde, M., Byrd, T., Shaffer, D.R., Ghazi, A., Brawley, V.S., Corder, A., Schonfeld, K., Koch, J., Dotti, G., Heslop, H.E., Gottschalk, S., Wels, W.S., Baker, M.L., and Ahmed, N. (2013). TanCAR: a novel bispecific chimeric antigen receptor for cancer immunotherapy. Mol Ther Nucleic Acids 21, 1611-1620.

Hong, H., Stastny, M., Brown, C., Chang, W.C., Ostberg, J.R., Forman, S.J., and Jensen, M.C. (2014). Diverse solid tumors expressing a restricted epitope of L1-CAM can be targeted by chimeric antigen receptor redirected T lymphocytes. J Immunother 37, 93-104.

Jacoby, E., Yang, Y., Qin, H., Chien, C.D., Kochenderfer, J.N., and Fry, T.J. (2015). Murine allogeneic CD19 CAR T-cells harbor potent anti-leukemic activity but have the potential to mediate lethal GVHD. Blood pii: blood-2015-2008-664250.

Jensen, M.C., Popplewell, L., Cooper, L.J., DiGiusto, D., Kalos, M., Ostberg, J.R., and Forman, S.J. (2010). Antitransgene rejection responses contribute to attenuated persistence of adoptively transferred CD20/CD19-specific chimeric antigen receptor redirected $\mathrm{T}$ cells in humans. Biol Blood Marrow Transplant 16, 1245-1256.

Kakarla, S., Chow, K.K., Mata, M., Shaffer, D.R., Song, X.T., Wu, M.F., Liu, H., Wang, L.L., Rowley, D.R., Pfizenmaier, K., and Gottschalk, S. (2013). Antitumor effects of chimeric receptor engineered human T cells directed to tumor stroma. Mol Ther 21, 1611-1620.

Kalos, M., Levine, B.L., Porter, D.L., Katz, S., Grupp, S.A., Bagg, A., and June, C.H. (2011). T cells with chimeric antigen receptors have potent antitumor effects and can establish memory in patients with advanced leukemia. Sci Transl Med 3, 95ra73.

Kershaw, M.H., Wang, G., Westwood, J.A., Pachynski, R.K., Tiffany, H.L., Marincola, F.M., Wang, E., Young, H.A., Murphy, P.M., and Hwu, P. (2002). Redirecting migration of T cells to chemokine secreted from tumors by genetic modification with CXCR2. Hum Gene Ther 13, 1971-1980.

Kershaw, M.H., Westwood, J.A., Parker, L.L., Wang, G., Eshhar, Z., Mavroukakis, S.A., White, D.E., Wunderlich, J.R., Canevari, S., Rogers-Freezer, L., Chen, C.C., Yang, J.C., Rosenberg, S.A., and Hwu, P. (2006). A phase I study on adoptive immunotherapy using gene-modified $\mathrm{T}$ cells for ovarian cancer. Clin Cancer Res 12, 6106-6115.

Khaleghi, S., Rahbarizadeh, F., Ahmadvand, D., Rasaee, M.J., and Pognonec, P. (2012). A caspase 8-based suicide switch induces apoptosis in nanobody-directed chimeric receptor expressing $\mathrm{T}$ cells. Int J Hematol 95, 434-444.

Kloss, C.C., Condomines, M., Cartellieri, M., Bachmann, M., and Sadelain, M. (2013). Combinatorial antigen recognition with balanced signaling promotes selective tumor eradication by engineered $\mathrm{T}$ cells. Nat Biotechnol 31, 71-75.

Kobayashi, E., Kishi, H., Ozawa, T., Hamana, H., Nakagawa, H., Jin, A., Lin, Z., and Muraguchi, A. (2014). A chimeric antigen receptor for TRAIL-receptor 1 induces apoptosis in various types of tumor cells. Biochem Biophys Res Commun 453, 798-803.

Krug, C., Birkholz, K., Paulus, A., Schwenkert, M., Schmidt, P., Hoffmann, N., Hombach, A., Fey, G., Abken, H., Schuler, G., Schuler-Thurner, B., Dorrie, J., and Schaft, N. (2015). Stability and activity of MCSP-specific chimeric antigen receptors (CARs) depend on the $\mathrm{scFv}$ antigen-binding domain and the protein backbone. Cancer Immunol Immunother 64, 1623-1635.

Lamers, C.H., Sleijfer, S., van Steenbergen, S., van Elzakker, P., van Krimpen, B., Groot, C., Vulto, A., den Bakker, M., Oosterwijk, E., Debets, R., and Gratama, J.W. (2013). Treatment of metastatic renal cell carcinoma with CAIX CAR-engineered T cells: clinical evaluation and management of on-target toxicity. Mol Ther 21, 904-912.

Lamers, C.H., Sleijfer, S., Vulto, A.G., Kruit, W.H., Kliffen, M., Debets, R., Gratama, J.W., Stoter, G., and Oosterwijk, E. (2006). Treatment of metastatic renal cell carcinoma with autologous T-lymphocytes genetically retargeted against carbonic anhydrase IX: first clinical experience. J Clin Oncol 24, e20-e22.

Lamers, C.H., Willemsen, R., van Elzakker, P., van SteenbergenLangeveld, S., Broertjes, M., Oosterwijk-Wakka, J., Oosterwijk, E., Sleijfer, S., Debets, R., and Gratama, J.W. (2011). Immune responses to transgene and retroviral vector in patients treated with ex vivo- engineered T cells. Blood 117, 72-82.

Lanitis, E., Dangaj, D., Hagemann, I.S., Song, D.G., Best, A., Sandaltzopoulos, R., Coukos, G., and Powell, D.J., Jr. (2012a). Primary human ovarian epithelial cancer cells broadly express HER2 at immunologically-detectable levels. PLoS One 7, e49829.

Lanitis, E., Poussin, M., Hagemann, I.S., Coukos, G., Sandaltzopoulos, R., Scholler, N., and Powell, D.J., Jr. (2012b). Redirected antitumor activity of primary human lymphocytes transduced with a fully human anti-mesothelin chimeric receptor. Mol Ther 20, 633-643.

Lasek, W., Zagozdzon, R., and Jakobisiak, M. (2014). Interleukin 12: still a promising candidate for tumor immunotherapy? Cancer Immunol Immunother 63, 419-435.

Lee, D.W., Kochenderfer, J.N., Stetler-Stevenson, M., Cui, Y.K., Delbrook, C., Feldman, S.A., Fry, T.J., Orentas, R., Sabatino, M., Shah, N.N., Steinberg, S.M., Stroncek, D., Tschernia, N., Yuan, C., Zhang, H., Zhang, L., Rosenberg, S.A., Wayne, A.S., and Mackall, C.L. (2014). T cells expressing CD19 chimeric antigen receptors for acute lymphoblastic leukaemia in children and young adults: a phase 1 dose-escalation trial. Lancet 385, 517-528.

Liao, C., Xiao, W., Zhu, N., Liu, Z., Yang, J., Wang, Y., and Hong, M. (2015). Radiotherapy suppressed tumor-specific recruitment of regulator $\mathrm{T}$ cells via up-regulating microR-545 in Lewis lung carcinoma cells. Int J Clin Exp Pathol 8, 2535-2544.

Liu, F., Park, P.J., Lai, W., Maher, E., Chakravarti, A., Durso, L., Jiang, X., Yu, Y., Brosius, A., Thomas, M., Chin, L., Brennan, C., DePinho, R.A., Kohane, I., Carroll, R.S., Black, P.M., and Johnson, M.D. (2006). A genome-wide screen reveals functional gene clusters in the cancer genome and identifies EphA2 as a mitogen in glioblastoma. Cancer Res 66, 10815-10823

Liu, X., Jiang, S., Fang, C., Yang, S., Olalere, D., Pequignot, E.C., Cogdill, A.P., Li, N., Ramones, M., Granda, B., Zhou, L., Loew, A., Young, R.M., June, C.H., and Zhao, Y. (2015). Affinity-tuned ErbB2 or EGFR chimeric antigen receptor $\mathrm{T}$ cells exhibit an increased therapeutic index against tumors in mice. Cancer Res 75, 3596-3607.

Mata, M., Vera, J.F., Gerken, C., Rooney, C.M., Miller, T., Pfent, C., Wang, L.L., Wilson-Robles, H.M., and Gottschalk, S. (2014). Toward immunotherapy with redirected $\mathrm{T}$ cells in a large animal model: ex vivo activation, expansion, and genetic modification of canine $\mathrm{T}$ cells. $\mathrm{J}$ Immunother 37, 407-415.

Miao, H., Choi, B.D., Suryadevara, C.M., Sanchez-Perez, L., Yang, S., De Leon, G., Sayour, E.J., McLendon, R., Herndon, J.E., 2nd, Healy, P., Archer, G.E., Bigner, D.D., Johnson, L.A., and Sampson, J.H. (2014). EGFRvIII-specific chimeric antigen receptor T cells migrate to and kill tumor deposits infiltrating the brain parenchyma in an invasive xenograft model of glioblastoma. PLoS One 9, e94281.

Miao, H., Li, D.Q., Mukherjee, A., Guo, H., Petty, A., Cutter, J., Basilion, J.P., Sedor, J., Wu, J., Danielpour, D., Sloan, A.E., Cohen, M.L., and Wang, B. (2009). EphA2 mediates ligand-dependent inhibition and ligand-independent promotion of cell migration and invasion via a reciprocal regulatory loop with Akt. Cancer Cell 16, 9-20.

Moon, E.K., Wang, L.C., Dolfi, D.V., Wilson, C.B., Ranganathan, R., Sun, J., Kapoor, V., Scholler, J., Puré, E., and Milone, M.C. (2014). Multifactorial T-cell hypofunction that is reversible can limit the efficacy of chimeric antigen receptor-transduced human $\mathrm{T}$ cells in solid tumors. Clin Cancer Res 20, 4262-4273.

Morgan, R.A., Yang, J., Kitano, M., Dudley, M.E., Laurencot, C.M., and Rosenberg, S.A. (2010). Case report of a serious adverse event following the administration of $\mathrm{T}$ cells transduced with a chimeric antigen receptor recognizing ERBB2. Mol Ther 18, 843-851.

Ahmed, N.M., Brawley, V.S., Diouf, O., Ghazi, A., Yi, J., Liu, H., Rooney, C.M., Gianpietro, D., Gee, A.P., Grossman, R., Kew, Y., Baskin, D.S., Ashoori, A., Zhang, J., Hicks, J., Powell, S., Wels, W., Brenner, M.K., Heslop, H.E., and Gottschalk, S.M. (2015). Autologous HER2 CMV bispecific CAR $\mathrm{T}$ cells are safe and demonstrate clinical benefit for glioblastoma in a Phase I trial. J Immunol Therapy Cancer 3 (suppl 2), O11.

Park, J.R., Digiusto, D.L., Slovak, M., Wright, C., Naranjo, A., Wagner, J., Meechoovet, H.B., Bautista, C., Chang, W., Ostberg, J.R., and Jensen, M.C. (2007). Adoptive transfer of chimeric antigen receptor re-directed 
cytolytic T lymphocyte clones in patients with neuroblastoma. Mol Ther 15, 825-833.

Pule, M.A., Savoldo, B., Myers, G.D., Rossig, C., Russell, H.V., Dotti, G., Huls, M.H., Liu, E., Gee, A.P., Mei, Z., Yvon, E., Weiss, H.L., Liu, H., Rooney, C.M., Heslop, H.E., and Brenner, M.K. (2008). Virus-specific $\mathrm{T}$ cells engineered to coexpress tumor-specific receptors: persistence and antitumor activity in individuals with neuroblastoma. Nat Med 14, 1264-1270.

Russo, V., Bondanza, A., Ciceri, F., Bregni, M., Bordignon, C., Traversari, C., and Bonini, C. (2012). A dual role for genetically modified lymphocytes in cancer immunotherapy. Trends Mol Med 18, 193-200.

Schumacher, T.N., and Schreiber, R.D. (2015). Neoantigens in cancer immunotherapy. Science 348, 69-74.

Maude, S.L., Frey, N., Shaw, P.A., Aplenc, R., Barrett, D.M., Bunin, N.J., Chew, A., Gonzalez, V.E., Zheng, Z., Lacey, S.F., Mahnke, Y.D., Melenhorst, J.J., Rheingold, S.R., Shen, A., Teachey, D.T., Levine, B.L., June, C.H., Porter, D.L., and Grupp, S.A. (2014). Chimeric antigen receptor $\mathrm{T}$ cells for sustained remissions in leukemia. $\mathrm{N}$ Engl J Med 371, 1507-1517.

Krebs, S., Chow, K.K., Yi, Z., Rodriguez-Cruz T., Hegde M., Gerken C., Ahmed N., and Gottschalk, S. (2014). T cells redirected to interleukin-13Ra2 with interleukin-13 muteinechimeric antigen receptors have anti-glioma activity but also recognize interleukin-13Ra1. Cytotherapy 16, 1121-1131.

Song, D.G., Ye, Q., Carpenito, C., Poussin, M., Wang, L., Ji, C., Figini, M., June, C.H., Coukos, G., and Powell, D.J., Jr. (2011). In vivo persistence, tumor localization, and antitumor activity of CAR-engineered $\mathrm{T}$ cells is enhanced by costimulatory signaling through CD137 (4-1BB). Cancer Res 71, 4617-4627.

Spear, P., Barber, A., Rynda-Apple, A., and Sentman, C.L. (2013). NKG2D CAR T-cell therapy inhibits the growth of NKG2D ligand heterogeneous tumors. Immunol Cell Biol 91, 435-440.

Stancovski, I., Schindler, D.G., Waks, T., Yarden, Y., Sela, M., and Eshhar, Z. (1993). Targeting of $T$ lymphocytes to Neu/HER2expressing cells using chimeric single chain Fv receptors. J Immunol 151, 6577-6582.

Stephan, M.T., Ponomarev, V., Brentjens, R.J., Chang, A.H., Dobrenkov, K.V., Heller, G., and Sadelain, M. (2007). T cell-encoded CD80 and 4-1BBL induce auto- and transcostimulation, resulting in potent tumor rejection. Nat Med 13, 1440-1449.

Sun, M., Shi, H., Liu, C., Liu, J., Liu, X., and Sun, Y. (2014). Construction and evaluation of a novel humanized HER2-specific chimeric receptor. Breast Cancer Res 16, R61.

Tang, X., Zhou, Y., Li, W., Tang, Q., Chen, R., Zhu, J., and Feng, Z. (2014). T cells expressing a LMP1-specific chimeric antigen receptor mediate antitumor effects against LMP1-positive nasopharyngeal carcinoma cells in vitro and in vivo. J Biomed Res 28, 468-475.

Anurathapan, U., Chan, R.C., Hindi, H.F., Mucharla, R., Bajgain, P.,
Hayes, B.C., Fisher, W.E., Heslop, H.E., Rooney, C.M., Brenner, M.K., Leen, A.M., and Vera, J.F. (2013). Kinetics of tumor destruction by chimeric antigen receptormodified T cells. Mol Ther 22, 623-633.

VanSeggelen, H., Hammill, J.A., Dvorkin-Gheva, A., Tantalo, D.G., Kwiecien, J.M., Denisova, G.F., Rabinovich, B., Wan, Y., and Bramson, J.L. (2015). T cells engineered with chimeric antigen receptors targeting NKG2D ligands display lethal toxicity in mice. Mol Ther 23, 1600-1610.

Wang, W., Ma, Y., Li, J., Shi, H., Wang, L., Guo, F., Zhang, J., Li, D., Mo, B., Wen, F., Liu, T., Liu, Y., Wang, Y., and Wei, Y. (2013). Specificity redirection by CAR with human VEGFR-1 affinity endows $T$ lymphocytes with tumor-killing ability and anti-angiogenic potency. Gene Ther 20, 970-978.

Watford, W.T., Moriguchi, M., Morinobu, A., and O'Shea, J.J. (2003). The biology of IL-12: coordinating innate and adaptive immune responses. Cytokine Growth Factor Rev 14, 361-368.

Wilkie, S., Picco, G., Foster, J., Davies, D.M., Julien, S., Cooper, L., Arif, S., Mather, S.J., Taylor-Papadimitriou, J., Burchell, J.M., and Maher, J. (2008). Retargeting of human T cells to tumor-associated MUC1: the evolution of a chimeric antigen receptor. J Immunol 180, 4901-4909.

Wu, C.Y., Roybal, K.T., Puchner, E.M., Onuffer, J., and Lim, W.A. (2015a). Remote control of therapeutic $\mathrm{T}$ cells through a small molecule-gated chimeric receptor. Science 350, aab4077.

Wu, M., Zhang, T., Alcon, A., and Sentman, C.L. (2015b). DNAM-1-based chimeric antigen receptors enhance $\mathrm{T}$ cell effector function and exhibit in vivo efficacy against melanoma. Cancer Immunol Immunother 64, 409-418.

Wu, M., Zhang, T., DeMars, L.R., and Sentman, C.L. (2015c). B7H6-specific chimeric antigen receptors lead to tumor elimination and host antitumor immunity. Gene Ther 22, 675-684.

Yarden, Y., and Sliwkowski, M.X. (2001). Untangling the ErbB signalling network. Nat Rev Mol Cell Biol 2, 127-137.

Yvon, E., Del Vecchio, M., Savoldo, B., Hoyos, V., Dutour, A., Anichini, A., Dotti, G., and Brenner, M.K. (2009). Immunotherapy of metastatic melanoma using genetically engineered GD2-specific T cells. Clin Cancer Res 15, 5852-5860.

Zhang, T., Wu, M.R., and Sentman, C.L. (2012). An NKp30-based chimeric antigen receptor promotes $\mathrm{T}$ cell effector functions and antitumor efficacy in vivo. J Immunol 189, 2290-2299.

Zhao, Y., Moon, E., Carpenito, C., Paulos, C.M., Liu, X., Brennan, A.L., Chew, A., Carroll, R.G., Scholler, J., Levine, B.L., Albelda, S.M., and June, C.H. (2010). Multiple injections of electroporated autologous T cells expressing a chimeric antigen receptor mediate regression of human disseminated tumor. Cancer Res 70, 9053-9061.

Zhou, X., Li, J., Wang, Z., Chen, Z., Qiu, J., Zhang, Y., Wang, W., Ma, Y., Huang, N., Cui, K., and Wei, Y. (2013). Cellular immunotherapy for carcinoma using genetically modified EGFR-specific T lymphocytes. Neoplasia 15, 544-553.

Open Access This article is distributed under the terms of the Creative Commons Attribution License which permits any use, distribution, and reproduction in any medium, provided the original author(s) and source are credited. 